\title{
Female (Under) Representation in Exercise Thermoregulation Research
}

\author{
Kate P. Hutchins ${ }^{1 *}$ (D) David N. Borg ${ }^{2} \mathbb{D}$, Aaron J. E. Bach ${ }^{3}$ D, Joshua J. Bon ${ }^{4,5}$ (D) Geoffrey M. Minett ${ }^{1}$ (D) and
} Ian B. Stewart ${ }^{1}$ (1)

\begin{abstract}
Background: Despite an increasing rate of women participating in professional sports, emergency services, and military settings where they are exposed to exertional heat stress, our understanding of female thermoregulation and the detrimental effects of heat on women's performance, especially regarding the menstrual cycle, is limited. This review aimed to quantify the representation of women in exercise thermoregulation research between 2010 and 2019 and the frequency that these articles reported details pertaining to female participants' menstrual cycle to determine the volume of novel research that is directly relevant to this growing population.

Methods: Original exercise thermoregulatory studies published in three major sports medicine databases (PubMed, MEDLINE, and SPORTDiscus) between 2010 and 2019 were surveyed. Articles were screened to determine the number of female and male participants in the study and whether studies involving women reported menstrual orientation or phase. Research involving healthy adult participants and an exercise protocol with a thermoregulatory outcome measure were included in the review.

Results: A total of 1407 articles were included in the review, involving 28,030 participants. The annual representation of women ranged from a mean of 11.6\% [95\% credible interval (Cl); 9.2, 14.3$]$ to $17.8 \%$ [95\% Cl; 15.2, 20.6] across the 10 years, indicating studies predominantly included men. Nonetheless, there was a small statistical increase in the overall proportion of women, with a mean overall proportion change of $0.7 \%[95 \% \mathrm{Cl} ; 0.2,1.2]$ per year. The increase appeared to be driven by a reduction in the number of studies including only men, rather than studies including more women alongside men, or increased women-only studies. Less than one third of articles involving women reported the menstrual orientation of participants and less than one quarter reported both menstrual orientation and phase.

Summary/Conclusion: This study shows that women were proportionally underrepresented in exercise thermoregulation research during the past decade and the majority of studies did not report menstrual cycle details of female participants. Researchers should consider including women in future work where their inclusion could contribute meaningful data that enhance the evidence-based and ultimately improves our comprehension of women's thermal physiology.
\end{abstract}

Keywords: Exertional heat stress, Menstrual cycle, Performance, Sex differences, Temperature

\footnotetext{
*Correspondence: k.hutchins@qut.edu.au

'Institute of Health and Biomedical Innovation, School of Exercise and Nutrition Sciences, Queensland University of Technology, Brisbane, Australia

Full list of author information is available at the end of the article
}

\section{Springer Open}

(c) The Author(s). 2021 Open Access This article is licensed under a Creative Commons Attribution 4.0 International License, which permits use, sharing, adaptation, distribution and reproduction in any medium or format, as long as you give appropriate credit to the original author(s) and the source, provide a link to the Creative Commons licence, and indicate if changes were made. The images or other third party material in this article are included in the article's Creative Commons licence, unless indicated otherwise in a credit line to the material. If material is not included in the article's Creative Commons licence and your intended use is not permitted by statutory regulation or exceeds the permitted use, you will need to obtain permission directly from the copyright holder. To view a copy of this licence, visit http://creativecommons.org/licenses/by/4.0/. 


\section{Key Points}

- Women are significantly underrepresented in the exercise thermoregulation literature over the past decade, accounting for only $30 \%$ of the total participants in 2019.

- The study of women's exercise thermoregulation increased between 2010 and 2019, and this proportional change was explained by less men-only studies rather than increased involvement of women.

- Instead of independent study, under-representative female samples are included in mixed-sex groups, with the median sample size of women and men subgroups being six and ten, respectively.

- Despite limited and conflicting data on the effect of the menstrual cycle on thermoregulatory functions, less than $30 \%$ of articles reported women's menstrual orientations and only $22 \%$ reported both menstrual orientation and phase.

\section{Background}

Males and females are defined by their innate anatomical and physiological characteristics $[1,2]$. Each sex is often studied independently, especially in exercise science and sports medicine, to avoid sex-related confounding effects $[3,4]$. For example, disparities between the sexes have been shown with muscle-tendon adaptations [5], injury susceptibility [6,7], and decision making under pressure [8]. Interestingly, both similarities and differences between the sexes are evidenced in the exercise thermoregulation literature.

Men and women respond to heat stress much the same when the rate of metabolic heat production is appropriately fixed $[9,10]$. Individual variability in temperature regulation during tasks without a fixed internal heat load is mainly due to morphological and fitness-related characteristics altering internal heat production and the heat loss required to attain heat balance $[9,11]$. Sex differences are noted in the size and density of sweat glands $[12,13]$ and sweat output at elevated requirements for heat loss $[9,14]$. In women, the thermoregulatory system is also in a continuous state of change across the menstrual cycle. As the concentrations of reproductive hormones shift, so too does core temperature, along with modifications to the onset thresholds and sensitivity of autonomic heat loss responses [15-17]. Multiple recent works have failed to reveal any large effects of the menstrual cycle on heat dissipation during exercise tasks [18-20]. However, given limited data availability and the poor validity of some previous studies [18], the certainty of this conclusion is not without reservation. Thus, it remains undetermined if sex-based differences relating to the sudomotor function and the menstrual cycle make women more susceptible to performance deficits in the heat [21-23]. With more women entering physical occupations [24, 25], a drive for greater representation in emergency services [26, 27], increased professionalism of women in elite sport $[28,29]$, and extreme heat becoming more frequent [30], there is an impending need for further knowledge.

Anecdotally, exercise thermoregulation studies involving women appear to be growing. However, this has not been empirically confirmed. The sex bias and general omission of women reported in sports science literature [31] are also likely to be true in the area of exercise thermoregulation. High-quality thermoregulation studies involve complex study designs and will often require repeated data collection periods for participants. The additional time and resources required to appropriately control for any contraceptive, hormonal, or menstrual cycle influences in this field have likely contributed to the absence of women in previous work [32]. This study aimed to systematically review the representation of women in exercise thermoregulation literature between 2010 and 2019 to provide perspective on modern research practices. It was hypothesized that the proportion of women included in studies has not changed over this period. A concomitant aim was to determine how frequently these articles reported details pertaining to female participants' menstrual cycle or phase.

\section{Methods}

\section{Search Strategy}

The search was conducted according to the conventional systematic review processes to select appropriate literature and ensure the search reproducibility [33]. A list of keywords relevant to the research theme was created with the assistance of $\mathrm{MeSH}$ browsers, trialed, and refined until the most effective search statement was achieved. Three major sports medicine databasesPubMed, MEDLINE, and SPORTDiscus-were searched using the key terms, Boolean operators, and limits. The final list of search terms and complete search statement is provided in Supplementary 1.

\section{Inclusion Criteria}

Included studies (a) were published between January 2010 and December 2019, (b) had an accessible English abstract, (c) included original data (d) from healthy (i.e., free of acute or chronic disease) adult humans $(\geq 18$ years), (e) had a design that included any form of exercise or movement in the protocol, and (f) described a thermoregulatory outcome measure (Supplementary 1). Participants from studies using healthy control groups were included in the results. 


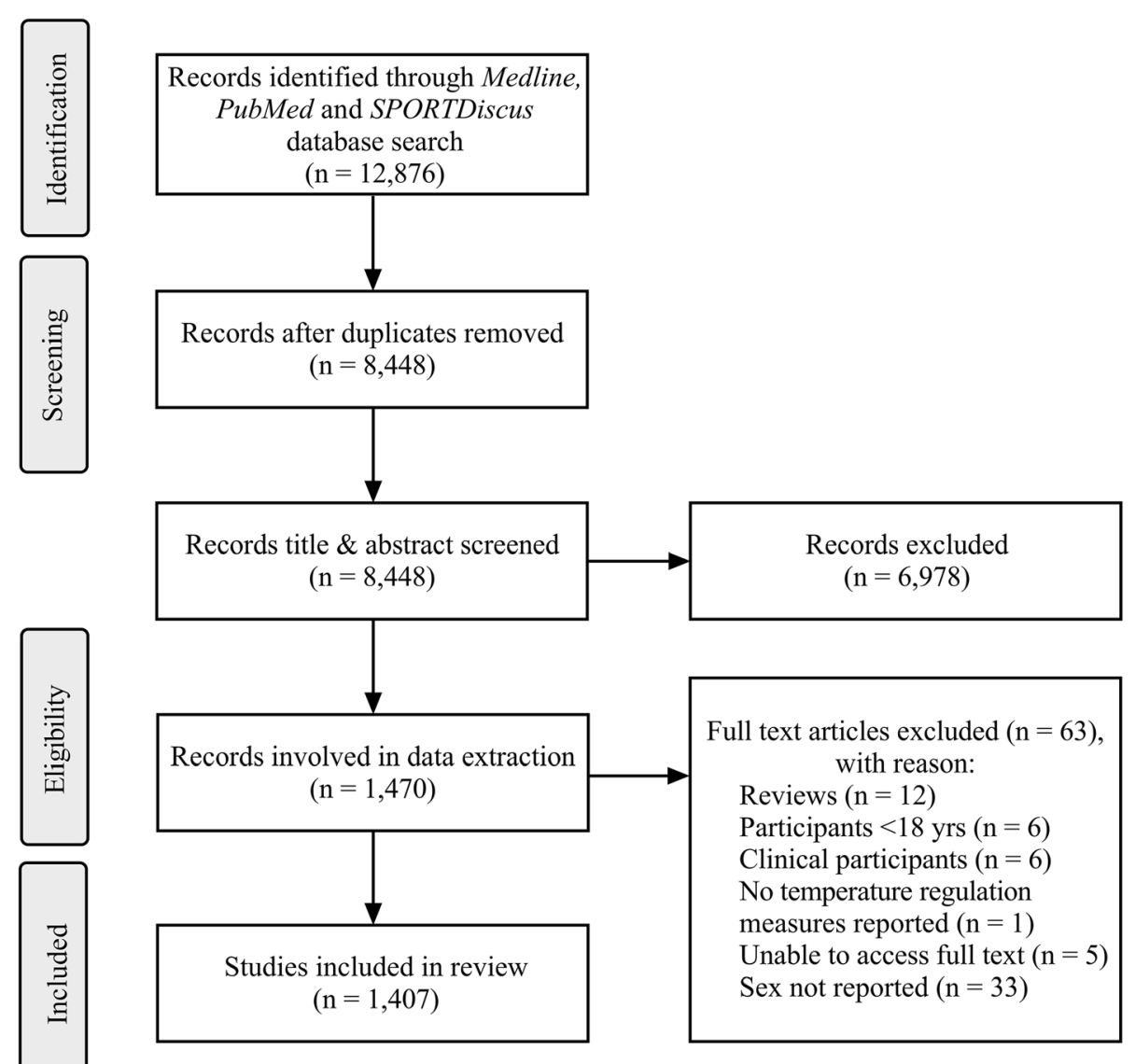

Fig. 1 PRISMA flow diagram of record search and data extraction

\section{Screening}

A total of 12,876 results were retrieved from the database searches on December 10, 2019-5818 from PubMed, 5917 from MEDLINE, and 1141 from SPORTDiscus (Fig. 1). Results were imported into Covidence (Covidence Systematics Review Software 2019, Veritas Health Innovation). Duplicates were removed, and titles and abstracts were screened. Two authors independently screened all articles against the inclusion criteria. Conflicts were resolved by a third author. A PRISMA flow diagram summarising the search process is provided in Fig. 1 [33].

\section{Data Extraction}

Eligible studies were exported to Excel (16.0, Microsoft Corp., Washington, USA), where the number of women and men in each study was extracted from the full text. Corresponding authors were contacted to clarify participant numbers and sex if such details were not explicitly stated in full text. The authors acknowledge that an individual's sex can change from birth, as in the case of transgender people. As such, the authors recorded if participants were specified to be transgender women or men and included them in the count of women and men respectively in the reviewed studies.

Secondary data extraction was completed on studies that involved women. From these studies, the following details were extracted whether menstrual orientation (i.e., natural menstruating, hormonal contraceptive user, pregnant, postmenopausal, oligomenorrheic, secondary amenorrheic cycles) was reported, the number of participants reported in these groups, and whether menstrual cycle phase was reported. The extraction process was completed by two authors. A list of the included studies can be accessed at https://github.com/katehutchins/ female-thermoreg-review.

\section{Data Analysis}

Descriptive statistics are reported as count and percent. The median (interquartile range; IQR) sample size of studies with only women, both men and women, and only men was calculated. The proportion of women included in studies was calculated using the equation: $n / N$, where $n$ is the number of women and $N$ is the total number of participants in the study. A proportion of 0 would indicate no women were included in a study, with 
1 indicating only women were included. Zero- and oneinflated beta (ZOIB) regression was used to investigate whether there was no change in the proportion of women included in studies between 2010 and 2019 [34]. A beta regression can model values between 0 and 1 (exclusive) and is often used to model proportional data $[34,35]$. ZOIB regression extends beta regression by allowing exact $0 \mathrm{~s}$ and $1 \mathrm{~s}$ to be observed, with some unknown probability.

As with generalized linear models (e.g., logistic regression), each parameter governing the ZOIB regression is connected to a linear regression equation (a linear combination of coefficients and covariates) via a link function. In this case, the logit link function was used for all components. The mean of the beta distribution, the probability of observing an exact 0 , and the probability of observing an exact 1 were each modeled with a distinct intercept and coefficient for the time covariate (on the linear scale). The shape of the beta distribution was estimated without covariates. For the regression coefficients, a normal (mean 0, precision 0.001) prior distribution was used. Details for the ZOIB model and implementation can be found in Liu and Kong [34], while our $\mathrm{R}$ [36] code to replicate the analysis can be found here https://github.com/katehutchins/femalethermoreg-review.

Logistic regression was used to determine whether the reporting of menstrual cycle orientation changed over the decade. For this model, a normal (mean 0, SD 1) prior distribution was used for the regression coefficient (i.e., year). For the ZOIB and logistic regression models, posterior summaries were estimated using Markov chain Monte Carlo (MCMC). Four chains of 250,000 samples

Table 1 The number of articles total and each group (women only, men only, sex aggregated studies (both)) annually from 2010 to 2019. Percentage relative to the total of each group also presented by year

\begin{tabular}{|c|c|c|c|c|c|c|c|}
\hline \multirow[t]{2}{*}{ Year } & \multirow{2}{*}{$\begin{array}{l}\text { Annual } \\
\text { Articles }\end{array}$} & \multicolumn{2}{|c|}{ Women Only } & \multicolumn{2}{|c|}{ Men Only } & \multicolumn{2}{|l|}{ Both } \\
\hline & & Article & $\%$ & Article & $\%$ & Article & $\%$ \\
\hline 2010 & 95 & 5 & 5.3 & 69 & 72.6 & 21 & 22.1 \\
\hline 2011 & 120 & 6 & 5.0 & 88 & 73.3 & 26 & 21.7 \\
\hline 2012 & 108 & 7 & 6.5 & 81 & 75.0 & 20 & 18.5 \\
\hline 2013 & 117 & 6 & 5.1 & 79 & 67.5 & 32 & 27.4 \\
\hline 2014 & 162 & 8 & 5.6 & 126 & 77.8 & 28 & 17.3 \\
\hline 2015 & 167 & 6 & 3.6 & 120 & 71.9 & 41 & 24.6 \\
\hline 2016 & 134 & 4 & 3.0 & 96 & 71.6 & 34 & 25.4 \\
\hline 2017 & 162 & 6 & 3.7 & 103 & 63.6 & 53 & 32.7 \\
\hline 2018 & 166 & 11 & 6.6 & 111 & 66.9 & 44 & 26.5 \\
\hline 2019 & 176 & 15 & 8.5 & 106 & 60.2 & 55 & 31.3 \\
\hline \multicolumn{2}{|c|}{ Decade Average } & 7.4 & 5.2 & 97.9 & 70.0 & 35.4 & 24.7 \\
\hline \multicolumn{2}{|c|}{ Standard Deviation } & 3.3 & 1.6 & 18.6 & 5.4 & 12.5 & 5.0 \\
\hline
\end{tabular}

were drawn after a burn-in period of 25,000 additional draws per chain. Before summaries from the posterior distribution were calculated, the MCMC chains were thinned by a factor of 10. Regression coefficients (on the logit scale) and proportions are reported as the posterior mean and 95\% credible interval (CI).

\section{Results}

Table 1 summarizes the number of articles each year, Table 2 summarizes the number and breakdown of participants included in these articles, and Fig. 2 depicts the number of men and women by year. The median sample size of studies including only women was 14 (IQR: 10$24)$. For studies including only men, the median sample size was 10 (IQR: 8-16). In studies including both sexes, the median sample size of men and women subgroups were 10 (IQR: 6-17) and 6 (IQR: 3-10), respectively. One transgender woman was identified and included in the count of women.

There was an increase in the overall proportion of women included in exercise thermoregulation research between 2010 and 2019 (Fig. 3), with a mean change in the overall proportion per year of $0.7 \%$ [95\% CI; $0.2 \%$, $1.2 \%]$. However, in 2019, the estimated proportion was only $17.8 \%$ [95\% CI; $15.2 \%, 20.6 \%$ ] (Fig. 3; Supplementary 2). The increase appeared to be driven by a reduction in the number of studies including no women $\left(\beta_{\{0\}}\right.$ $[95 \% \mathrm{CI}]=-0.07[-0.11,-0.03])$, rather than studies including a larger subgroup of women $\left(\beta_{(0,1)}[95 \% \mathrm{CI}]=\right.$ $0.01[-0.02,0.04])$, or an increase in the number of studies including only women $\left(\beta_{\{1\}}[95 \% \mathrm{CI}]=-0.01[-0.10\right.$, $0.07])$. Supplementary 3 shows the parameter estimates from the zero- and one-inflated beta distribution model.

A total of 422 studies included women. Of these, $72 \%$ did not report the menstrual orientation of their female participants. Reporting did not change across the decade $(\beta[95 \% \mathrm{CI}]=0.03[-0.05,0.10])$. Articles that reported orientation, most frequently involved groups of naturally menstruating women (64\%) and oral contraceptive users (26\%). Less than $5 \%$ of articles identified a group of an intrauterine device or implant users, pregnant or postmenopausal women, or women with secondary amenorrheic or oligomenorrheic cycles. Alongside menstrual orientation, the menstrual phase was controlled in $22 \%$ of articles involving women and participants were most often tested in the follicular (48\%), placebo pill (21\%), or early follicular phase (19\%).

\section{Discussion}

This article aimed to offer a perspective on research practices between 2010 and 2019 by determining the proportion of women included in exercise thermoregulation research. As hypothesized, studies predominantly recruited men, with the mean annual representation of 
Table 2 The number of participants total and each group (women only, men only, sex aggregated studies (both)) annually from 2010 to 2019. Percentage relative to the total of each group also presented by year

\begin{tabular}{|c|c|c|c|c|c|c|c|c|c|}
\hline \multirow[t]{2}{*}{ Year } & \multirow{2}{*}{$\begin{array}{l}\text { Annual } \\
\text { Participants }\end{array}$} & \multicolumn{2}{|l|}{ Women Only } & \multicolumn{2}{|l|}{ Men Only } & \multicolumn{4}{|l|}{ Both } \\
\hline & & Participants & $\%$ & Participants & $\%$ & Women & Men & Women \% & Men $\%$ \\
\hline 2010 & 1442 & 71 & 4.9 & 945 & 65.5 & 174 & 252 & 12.1 & 17.5 \\
\hline 2011 & 2080 & 173 & 8.3 & 1189 & 57.2 & 275 & 443 & 13.2 & 21.3 \\
\hline 2012 & 3109 & 211 & 6.8 & 2439 & 78.4 & 142 & 317 & 4.6 & 10.2 \\
\hline 2013 & 2009 & 97 & 4.8 & 1010 & 50.3 & 469 & 433 & 23.3 & 21.6 \\
\hline 2014 & 2859 & 112 & 3.9 & 2012 & 70.4 & 238 & 497 & 8.3 & 17.4 \\
\hline 2015 & 3240 & 179 & 5.5 & 1716 & 53.0 & 489 & 856 & 15.1 & 26.4 \\
\hline 2016 & 2667 & 104 & 3.9 & 1213 & 45.5 & 623 & 727 & 23.4 & 27.3 \\
\hline 2017 & 2959 & 69 & 2.3 & 1304 & 44.1 & 584 & 1,002 & 19.7 & 33.9 \\
\hline 2018 & 4102 & 304 & 7.4 & 2594 & 63.3 & 419 & 785 & 10.2 & 19.1 \\
\hline 2019 & 3563 & 488 & 13.7 & 1463 & 41.1 & 676 & 936 & 19.0 & 26.3 \\
\hline \multicolumn{2}{|c|}{ Decade Average } & 181 & 6.2 & 1589 & 56.9 & 409 & 625 & 14.9 & 22.1 \\
\hline \multicolumn{2}{|c|}{ Standard Deviation } & 130 & 3.2 & 585 & 12.3 & 192 & 268 & 6.4 & 6.6 \\
\hline
\end{tabular}

women deficient, ranging from 11.6 to $17.8 \%$ across the 10 years (Fig. 3; Supplementary 2). Studies generally included women alongside men rather than focusing specifically on women-only cohorts (Table 1 ). When both sexes were studied together, women represented a lower proportion of the total study sample than men (Table 2). An increase in the proportion of women studied was evident across the decade. Nevertheless, this is explained by a reduction of men-only studies, not greater inclusion of women per se (Supplementary 3). Women were most frequently tested in the follicular phase or placebo stage of the oral contraceptive pill. However, only $22 \%$ of studies involving women reported both menstrual orientation and phase. These results indicate that women require greater attention in exercise thermoregulation research.
Historically, the absence of women involved in sport was partly held responsible for the scarcity of sports science research involving female cohorts [37]. Despite increased sex parity in participation rates from grassroots through to the Olympic level $[28,29]$, women have remained underrepresented in modern sports medicine literature. A review of just three sports medicine journals from 2011 to 2013 found that women accounted for only $39 \%$ of the research participants [31]. Similarly, despite growing sport [28] and workplace participation rates [25-27] and the need for a greater evidence-based understanding of women's heat stress tolerance $[18,38]$, women continue to be underrepresented in exercise thermoregulation research-both as participants in studies and as the specific subject of scientific inquiry

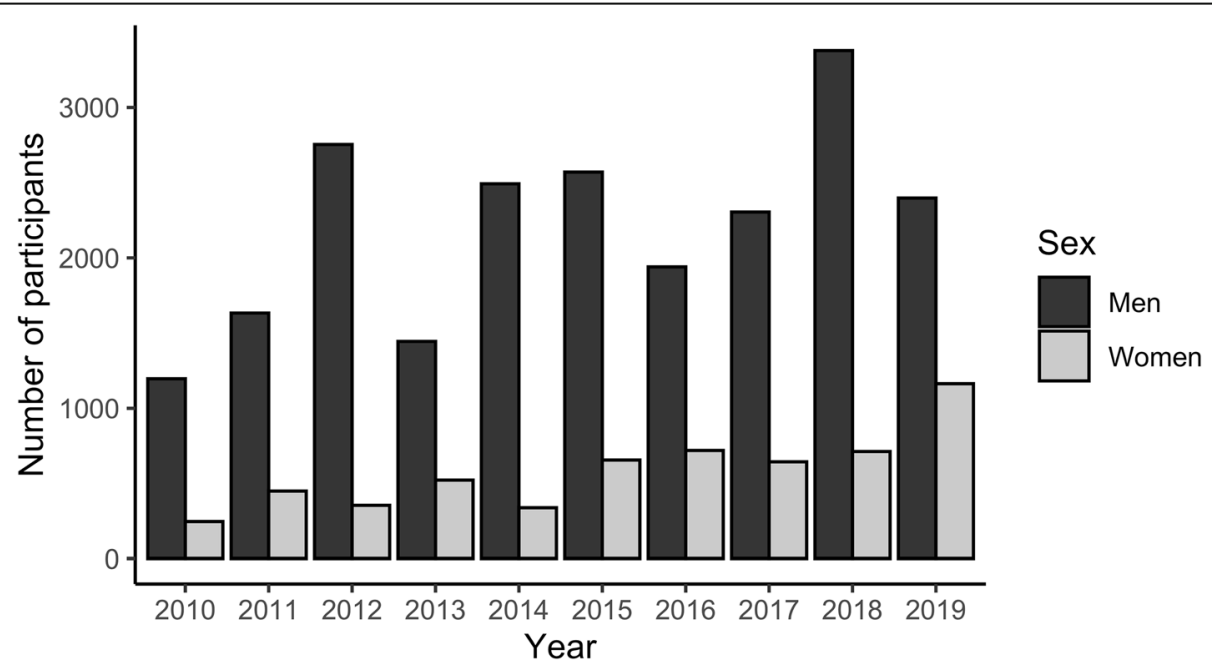

Fig. 2 The number of men and women as participants by year 


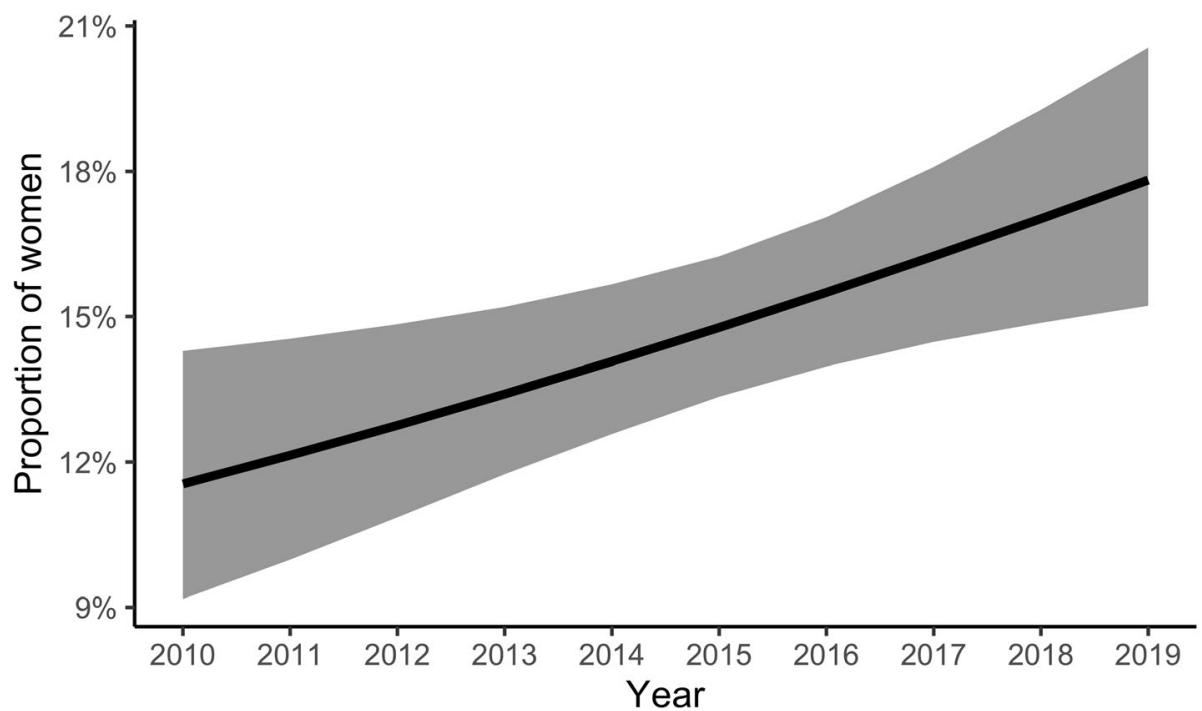

Fig. 3 The proportion of women in exercise thermoregulation studies between 2010 and 2019. The dark solid line indicates the mean and the shaded area the $95 \%$ credible interval

(Table 1, Fig. 2). This review further highlights that women's representation in this field has not improved across the decade (Fig. 3; Supplementary 2).

Methodological challenges encountered when testing women may explain their large absence from exercisebased thermoregulation research. Studying the interactions between the female reproductive system and thermoregulatory responses is difficult due to the innate complexity of dynamic hormonal shifts [38]. In naturally menstruating women, an elevation in basal core temperature (e.g., $0.3-0.5^{\circ} \mathrm{C}$ ) parallels the luteal phase when progesterone and estrogen peak, whereas a reduced core temperature occurs in the follicular phase when the only estrogen is elevated [39]. The core temperature threshold for autonomic heat loss mechanisms (i.e., peripheral vasodilation and sweating) and response sensitivity is believed to initiate later, at higher core temperatures, and occur at a slower rate during the luteal phase compared to the follicular [40, 41]. This would imply that the biphasic changes could aid (follicular) or hinder (luteal) heat loss mechanisms, and subsequently performance owing to their influence on core temperature [42].

This inter-system relationship is further complicated by women's ever-changing endocrine profile, which alters naturally with maturation [43] and the use of hormonal contraceptives [44]. Thus, it is logical that while gaps in our understanding of this area remain, researchers should be encouraged to collect and report the menstrual cycle orientation of participants. Such transparency would beneficially expand the pool of scientific data relevant to women in specific life stages and enable the research community to maximize the work's potential via data aggregation. Notably, the reporting of menstrual orientation did not occur in over $70 \%$ of the articles reviewed.

More evidence is needed to conclusively support or refute the effects of the menstrual phase on the rate of heat loss or onset threshold during exercise in hot environments [18, 19, 45]. For example, in recreationally active women, time to fatigue in hot, humid conditions [45], and exercise tolerance time in a hot, dry environment [46] were lower in the luteal than the follicular phase. More recent works have found that female reproductive hormones have trivial effects on the thermoregulatory system and exercise performance in the heat [18-20]. However, these articles, among others, acknowledge the need for continued investigation into both eumenorrheic women and hormonal contraceptive users [21, 38]. Martin and colleagues [47] showed that hormonal contraceptive use, especially oral contractive pill use, is highly prevalent in athletic women. While groups of oral contraceptive pill users were the second most frequently studied menstrual orientation identified in the literature reviewed in the current investigation, the proportion of these studies does not reflect the growing prevalence of oral contraceptive use nor the demand for research on exogenous, synthetic hormones [47].

A greater proportion of the articles that identified menstrual orientation also reported that the menstrual phase was controlled. This is a positive result as in controlling for phase, hormonal variability is reduced, and the effects of divergent hormonal concentrations can be examined at specific points in a cycle [48]. It should be noted that it is not always necessary to control the menstrual phase, for instance, when reproductive hormones 
(natural or synthetic) have been identified assuredly to have little or no effect on the study's primary outcome measure. However, correctly controlling for the menstrual phase is essential to improve the internal validity of the research [49]. Inconsistent findings between studies could result from alternate phase verification methods or testing on different days or phases of the cycle $[32,50]$.

Recent methodological recommendations and guides to best practice aim to minimize this study heterogeneity and improve the quality of future research involving women [48, 49]. For example, combining calendar counting with urinary ovulation tests and serial blood sampling [51] and tracking participants' menstrual cycle characteristics $\geq 2$ months before testing improves the accuracy of phase identification [48]. Unfortunately, access to the necessary facilities, cost of analysis, and an extended data collection timeline may restrict adherence to this advice. In the case of hormonal contraceptive users, different forms, types, and steroid concentrations, along with individual exogenous-endogenous hormone interactions, must also be considered $[48,52]$. The meticulous control measures and methodological considerations necessary to include women in thermoregulatory research and correctly control for menstrual phase may have deterred scientists from involving more women in their research over the past decade (Fig. 2, Table 1). However, without appropriate amendments to current research practice, aspects of female physiology-that meaningfully influence temperature regulation-will remain questioned or unidentified.

Based on the findings of this analysis, how can researchers best serve to increase women's representation and scientific knowledge? Firstly, recognition that while representation can be improved, women deserve to be included in research purposefully where their outcomes can contribute to scientific knowledge, not merely for the sake of equal representation. Secondly, researchers should consider whether previous research conclusively or inconclusively identifies differences between the sexes in their primary outcome variable(s) during the research development and design stage. For topics where sex differences remain inconclusive, designing a women-only or study with men and women would best serve to increase the scientific knowledge on women. Further, if both sexes are examined, the data of men and women should not be aggregated as the results could identify whether a sex difference on the topic exists. Finally, studies including women must subsequently choose whether to control for menstrual orientation and phase. Again, researchers should consider if natural or synthetic reproductive hormones have or have not conclusively been identified to influence the primary outcome variable(s).
In the current review, participants were most frequently tested in hormonal phases that exhibit a depressed hormonal profile when the effects of estrogen and progesterone on other physiological systems are minimized. Hence, it is reasonable to suggest that in some of these studies, testing was conducted in specific menstrual phases to reduce the potential confounding effects of reproductive hormones on the measure(s) of interest. This practice does not serve to improve our knowledge on this topic where more evidence on the relationship between the reproductive and thermoregulatory systems is required. For a comprehensive inventory of study design considerations and guidelines for testing women with different hormonal profiles see Elliot-Sale and colleagues' work [48].

It is clear from our analysis that future investigations involving women should include larger sample sizesthe median sample of studies including both sexes was extremely small (men, $n=10$; women, $n=6$ ). For context, a sample size of 6 per group has a mere $24 \%$ power-and 10 per group $40 \%$ power-to detect an effect size of 0.8 (often defined as a large effect), given $\alpha=$ $5 \%$. Sample size justifications (e.g., power analyses) require greater consideration as do analytical approaches that allow the evaluation of apparently null results (e.g., equivalence testing, Bayes factors) [53, 54]. We appreciate that practical, logistical, and financial reasons may preclude the recruitment of larger samples. When small samples are unavoidable, we recommend that researchers think carefully about their smallest effect size of interest [54], where possible, use equivalence testing to help draw substantive conclusions from a study's results [54]; and consider the use of fully Bayesian methods, to leverage the benefits of setting informative prior distributions [53], based on previous literature or expert elicitation [55]. Data aggregation and metaanalyses are additional strategies that can help alleviate small sample size concerns and improve sample bias corrections. Though methodological inconsistencies likely prevent most current studies from being pooled, this may be possible with future works [56]. The standardized reporting of individual hormonal concentrations may improve confidence when pooling results and assist with study interpretation (e.g., explaining outliers and unexpected results).

\section{Conclusion}

This review highlights the underrepresentation of women in the exercise thermoregulation literature between 2010 and 2019. This underrepresentation belies the growth in women active in sport and industry, and also the pressing need to expand the scientific evidence relevant to women. Further, the infrequency of reporting menstrual orientation and menstrual phase in the 
articles reviewed has provided an insightful perspective on current research practices and where improvements can be made. To facilitate increased knowledge in women's exercise thermoregulation research, the following practices could be improved: (i) transparent reporting of menstrual orientation, (ii) researchers should be conscious of the gaps in women's research and consider the purposeful inclusion of women in their work, (iii) improvements in data transparency for subsequent aggregation, and finally (iv) appropriate study planning, design, and analysis is vital.

\section{Abbreviations}

Cl: Credible interval; IQR: Interquartile range; MCMC: Markov chain Monte Carlo; ZOIB: Zero- and one-inflated beta

\section{Supplementary Information}

The online version contains supplementary material available at https://doi. org/10.1186/s40798-021-00334-6.

\section{Additional file 1 \\ Additional file 2. \\ Additional file 3.}

\section{Acknowledgements}

The authors would like to acknowledge the corresponding authors that assisted in confirming the sex of participants within their research.

\section{Code Availability}

The code that reproduces the findings of the study can be accessed at https://github.com/katehutchins/female-thermoreg-review.

\section{Authors' Contributions}

Study conception and design: KPH, GMM, and IBS. Data screening: KPH, AJEB, and IBS. Data extraction: $\mathrm{KPH}, \mathrm{DNB}$, and IBS. Data analysis: DNB and JJB. Wrote the manuscript: KPH and DNB. Edited manuscript: KPH, DNB, AJEB, JJB, GMM, and IBS. The authors read and approved the final manuscript.

\section{Funding}

This project was not financially supported.

\section{Availability of Data and Materials}

The data that reproduce the findings of the study can be accessed at https://github.com/katehutchins/female-thermoreg-review.

\section{Declarations}

Ethics Approval and Consent to Participate

Not applicable.

\section{Consent for Publication}

Not applicable.

\section{Competing Interests}

The authors, Kate Hutchins, David Borg, Aaron Bach, Joshua Bon, Geoffrey Minett, and lan Stewart, declare that they have no competing interests.

\section{Author details}

${ }^{1}$ Institute of Health and Biomedical Innovation, School of Exercise and Nutrition Sciences, Queensland University of Technology, Brisbane, Australia. ${ }^{2}$ The Hopkins Centre, Menzies Health Institute Queensland, Griffith University, Brisbane, Australia. ${ }^{3}$ The National Climate Change Adaption Research Facility, Griffith University, Gold Coast, Australia. ${ }^{4}$ School of Mathematical Sciences, Queensland University of Technology, Brisbane, Australia. ${ }^{5}$ Australian Centre of Excellence for Mathematical and Statistical Frontiers, Brisbane, Australia.
Received: 9 October 2020 Accepted: 6 June 2021

Published online: 22 June 2021

\section{References}

1. Krieger N. Genders, sexes, and health: what are the connections-and why does it matter? Int J Epidemiol. 2003;32(4):652-7. https://doi.org/10.1093/ije/ dyg 156.

2. Heidari S, Babor TF, De Castro P, Tort S, Curno M. Sex and gender equity in research: rationale for the sager guidelines and recommended use. Res Integrity Peer Rev. 2016;1(1):2. https://doi.org/10.1186/s41073-016-0007-6.

3. Tannenbaum C, Greaves L, Graham ID. Why sex and gender matter in implementation research. BMC Med Res Methodol. 2016;16(1):145. https:// doi.org/10.1186/s12874-016-0247-7.

4. Rich-Edwards JW, Kaiser UB, Chen GL, Manson JE, Goldstein JM. Sex and gender differences research design for basic, clinical, and population studies: essentials for investigators. Endocr Rev. 2018;39(4):424-39. https:// doi.org/10.1210/er.2017-00246.

5. Nakamura Y, Aizawa K. Sex hormones, menstrual cycle and resistance exercise. In: Hackney AC, editor. Sex hormones, exercise and women: scientific and clinical aspects. Cham: Springer; 2017. p. 243-56. https://doi. org/10.1007/978-3-319-44558-8_14.

6. Hewett TE, Ford KR, Hoogenboom BJ, Myer GD. Understanding and preventing acl injuries: current biomechanical and epidemiologic considerations - update 2010. N Am J Sports Phys Ther. 2010:5(4):234-51.

7. Gallagher V, Kramer N, Abbott K, Alexander J, Breiter H, Herrold A, et al. The effects of sex differences and hormonal contraception on outcomes after collegiate sports-related concussion. J Neurotrauma. 2018;35(11):1242-7. https://doi.org/10.1089/neu.2017.5453.

8. Pighin S, Savadori L, Bonini N, et al. Acute exercise increases sex differences in amateur athletes' risk taking. Int J Sports Med. 2015;36:858-63. https://doi. org/10.1055/s-0034-1398677.

9. Gagnon D, Kenny GP. Does sex have an independent effect on thermoeffector responses during exercise in the heat? J Physiol. 2012; 590(23):5963-73. https://doi.org/10.1113/jphysiol.2012.240739.

10. Nunneley SA. Physiological responses of women to thermal stress: a review. Med Sci Sports. 1978;10(4):250-5.

11. Notley SR, Lamarche DT, Meade RD, Flouris AD, Kenny GP. Revisiting the influence of individual factors on heat exchange during exercise in dry heat using direct calorimetry. Exp Physiol. 2019;104(7):1038-50. https://doi.org/1 $0.1113 /$ EP087666

12. Bar-Or O. Effects of age and gender on sweating pattern during exercise. Int J Sports Med. 1998;19:106-7. https://doi.org/10.1055/s-2007-971970.

13. Sato K, Sato F. Individual variations in structure and function of human eccrine sweat gland. Am J Physiol. 1983;245:203-8. https://doi.org/10.1152/a jpregu.1983.245.2.R203

14. Gagnon D, Crandall CG, Kenny GP. Sex differences in postsynaptic sweating and cutaneous vasodilation. J Appl Physiol. 2013;114:394 401. https://doi. org/10.1152/japplphysiol.00877.2012.

15. Stephenson LA, Kolka MA. Esophageal temperature threshold for sweating decreases before ovulation in premenopausal women. J Appl Physiol. 1999; 86:22-8. https://doi.org/10.1152/jappl.1999.86.1.22.

16. Charkoudian N, Johnson JM. Modification of active cutaneous vasodilation by oral contraceptive hormones. J Appl Physiol. 1997;83:2012-8. https://doi. org/10.1152/jappl.1997.83.6.2012

17. Charkoudian N, Stachenfeld N. Sex hormone effects on autonomic mechanisms of thermoregulation in humans. Auton Neurosci. 2016;196:7580. https://doi.org/10.1016/j.autneu.2015.11.004.

18. Giersch GE, Morrissey MC, Katch RK, et al. Menstrual cycle and thermoregulation during exercise in the heat: a systematic review and meta-analysis. J Sci Med Sport. 2020;23(12):1134-40. https://doi.org/10.1016/ j.jsams.2020.05.014.

19. Lei TH, Stannard SR, Perry BG, Schlader ZJ, Cotter JD, Mündel T. Influence of menstrual phase and arid vs. humid heat stress on autonomic and behavioural thermoregulation during exercise in trained but unacclimated women. J Physiol. 2017;595(9):2823-37. https://doi.org/10.1113/JP273176.

20. Notley SR, Dervis S, Poirier M, et al. Menstrual cycle phase does not modulate whole body heat loss during exercise in hot, dry conditions. J Appl Physiol. 2018:126:286-93. https://doi.org/10.1152/japplphysiol.00735.2018.

21. Minahan C, Melnikoff M, Quinn K, Larsen B. Response of women using oral contraception to exercise in the heat. Eur J Appl Physiol. 2017:117(7):138391. https://doi.org/10.1007/s00421-017-3628-7. 
22. Wenner MM, Stachenfeld NS. Sex hormones and environmental factors affecting exercise. In: Hackney AC, editor. Sex hormones, exercise and women: scientific and clinical aspects. Cham: Springer; 2017. p. 151-70. https://doi.org/10.1007/978-3-319-44558-8 9.

23. Corbett J, Wright J, Tipton MJ. Sex differences in response to exercise heat stress in the context of the military environment. BMJ Mil Health. 2020. https://doi.org/10.1136/jramc-2019-001253.

24. Ministry of Defence. Women in ground close combat (GCC) review paper. Institute of Naval Medicine. Available at: https://assets.publishing.service.gov. uk/government/uploads/system/uploads/attachment_data/file/389575/2 0141218_WGCC_Findings_Paper_Final.pdf. Accessed 18 Apr 2020.

25. Jahnke SA, Poston WS, Haddock CK, et al. The health of women in the US fire service. BMC Womens Health. 2012;12(1):39. https://doi.org/10.1186/14 72-6874-12-39

26. Krusel N, Bissinella J. Male champions of change fire and emergency progress report 2017-18. Australasian Fire and Emergency Service Authorities Council. Available at: http://malechampionsofchange.com/wpcontent/uploads/2018/12/MCC-Fire-and-Emergency-Progress-Report-2018. pdf. Accessed 18 Apr 2020

27. Brushlinsky N, Ahrens M, Solokov S, et al. World fire statistics. International Association of Fire and Rescue Services. Available at: https://www.ctif.org/ sites/default/files/ctif_report22_world_fire_statistics_2017.pdf. Accessed 18 Apr 2020.

28. Fink JS. Female athletes, women's sport, and the sport media commercial complex: have we really "come a long way, baby"? Sport Manage Rev. 2015; 18(3):331-42. https://doi.org/10.1016/j.smr.2014.05.001.

29. Pfister $\mathrm{G}$. Women in sport - gender relations and future perspectives. Sport Soc. 2010;13(2):234-48. https://doi.org/10.1080/17430430903522954.

30. Hansen J, Sato M, Ruedy R, Lo K, Lea DW, Medina-Elizade M. Global temperature change. Proc Natl Acad Sci USA. 2006;103(39):14288-93. https://doi.org/10.1073/pnas.0606291103.

31. Costello JT, Bieuzen F, Bleakley CM. Where are all the female participants in sports and exercise medicine research? Eur J Sport Sci. 2014;14(8):847-51. https://doi.org/10.1080/17461391.2014.911354

32. Sims ST, Heather AK. Myths and methodologies: reducing scientific design ambiguity in studies comparing sexes and/or menstrual cycle phases. Exp Physiol. 2018;103(10):1309-17. https://doi.org/10.1113/EP086797.

33. Moher D, Liberati A, Tetzlaff J, Altman DG, The PRISMA Group. Preferred reporting items for systematic reviews and meta-analyses: the PRISMA statement. PLoS Med. 2009;6(7):e1000097. https://doi.org/10.1371/journal. pmed. 1000097.

34. Liu F, Kong Y. ZOIB: an R package for bayesian inference for beta regression and zero/one inflated beta regression. R Journal. 2015;7(2):34. https://doi. org/10.32614/RJ-2015-019.

35. Smithson M, Verkuilen J. A better lemon squeezer? Maximum-likelihood regression with beta-distributed dependent variables. Psychol Methods. 2006;11(1):54-71. https://doi.org/10.1037/1082-989X.11.1.54

36. R Core Team. R: a language and environment for statistical computing. $R$ foundation for Statistical Computing, Vienna, Austria 2020; https://www.Rproject.org/.

37. Charkoudian N, Stachenfeld NS. Reproductive hormone influences on thermoregulation in women. Compr Physiol. 2014;4(2):793-804. https://doi. org/10.1002/cphy.c130029.

38. Baker FC, Siboza F, Fuller A. Temperature regulation in women: effects of the menstrual cycle. Temperature. 2020;1:1-37. https://doi.org/10.1080/2332 8940.2020 .1735927$.

39. Marshall J. Thermal changes in the normal menstrual cycle. Br Med J. 1963; 1(5323):102-4. https://doi.org/10.1136/bmj.1.5323.102.

40. Stephenson LA, Kolka MA. Menstrual cycle phase and time of day alter reference signal controlling arm blood flow and sweating. Am J Physiol. 1985;249:186-91. https://doi.org/10.1152/ajpregu.1985.249.2.R186.

41. Inoue $Y$, Tanaka Y, Omori K, Kuwahara T, Ogura Y, Ueda H. Sex- and menstrual cycle-related differences in sweating and cutaneous blood flow in response to passive heat exposure. Eur J Appl Physiol. 2005;94(3):323-32. https://doi.org/10.1007/s00421-004-1303-2

42. Charkoudian N, Joyner MJ. Physiologic considerations for exercise performance in women. Clin Chest Med. 2004;25(2):247-55. https://doi.org/1 0.1016/j.ccm.2004.01.001.

43. Sherman BM, Korenman SG. Hormonal characteristics of the human menstrual cycle throughout reproductive life. J Clin Invest. 1975;55(4):699706. https://doi.org/10.1172/JCl107979.
44. Elliott-Sale K, Hicks K. Hormonal-based contraception and the exercising female. In: Forsyth J, Roberts CM, editors. The exercising female: science and its application. Routledge: Taylor and Francis; 2018. p. 30-43. https://doi. org/10.4324/9781351200271-4

45. de Jonge XAJ, Thompson MW, Chuter VH, et al. Exercise performance over the menstrual cycle in temperate and hot, humid conditions. Med Sci Sports Exerc. 2012;44(11):2190-8. https://doi.org/10.1249/MSS.0b013e3182 $656 f 13$.

46. Tenaglia SA, McLellan TM, Klentrou PP. Influence of menstrual cycle and oral contraceptives on tolerance to uncompensable heat stress. Eur J Appl Physiol Occup Physiol. 1999;80(2):76-83. https://doi.org/10.1007/s00421 0050561.

47. Martin D, Sale C, Cooper SB, Elliott-Sale KJ. Period prevalence and perceived side effects of hormonal contraceptive use and the menstrual cycle in elite athletes. Int J Sports Physiol Perform. 2018;13(7):926-32. https://doi.org/1 0.1123/ijspp.2017-0330

48. Elliott-Sale KJ, Minahan $\mathrm{CL}$, de Jonge XAJ, et al. Methodological considerations for studies in sport and exercise science with women as participants: a working guide for standards of practice for research on women. Sports Med. 2021;51(5):843-61. https://doi.org/10.1007/s40279-02101435-8.

49. de Jonge XAJ, Thompson B, Han A. Methodological recommendations for menstrual cycle research in sports and exercise. Med Sci Sports Exerc. 2019; 51(12):2610-7. https://doi.org/10.1249/MSS.0000000000002073.

50. Stachenfeld NS, Taylor HS. Challenges and methodology for testing young healthy women in physiological studies. Am J Physiol Endocrinol Metab. 2014;306:849-53. https://doi.org/10.1152/ajpendo.00038.2014.

51. Schaumberg MA, Jenkins DG, de Jonge XAJ, et al. Three-step method for menstrual and oral contraceptive cycle verification. J Sci Med Sport. 2017; 20(11):965-9. https://doi.org/10.1016/j.jsams.2016.08.013.

52. Elliott-Sale KJ, Smith S, Bacon J, Clayton D, McPhilimey M, Goutianos G, et al Examining the role of oral contraceptive users as an experimental and/or control group in athletic performance studies. Contraception. 2013;88(3): 408-12. https://doi.org/10.1016/j.contraception.2012.11.023.

53. Kruschke JK, Liddell TM. The bayesian new statistics: hypothesis testing, estimation, meta-analysis, and power analysis from a bayesian perspective. Psychon Bull Rev. 2018;25(1):178-206. https://doi.org/10.3758/s13423-01 6-1221-4.

54. Lakens D, Scheel AM, Isager PM. Equivalence testing for psychological research: a tutorial. Adv Methods Pract Psychol Sci. 2018;1(2):259-69. https:// doi.org/10.1177/2515245918770963.

55. Kuhnert PM, Martin TG, Griffiths SP. A guide to eliciting and using expert knowledge in Bayesian ecological models. Ecol Lett. 2010;13(7):900-14. https://doi.org/10.1111/j.1461-0248.2010.01477.x.

56. Choudhury S, Fishman JR, McGowan ML, et al. Big data, open science and the brain: lessons learned from genomics. Front Hum Neurosci. 2014:8:239. https://doi.org/10.3389/fnhum.2014.00239.

\section{Publisher's Note}

Springer Nature remains neutral with regard to jurisdictional claims in published maps and institutional affiliations.

\section{Submit your manuscript to a SpringerOpen ${ }^{\circ}$ journal and benefit from:}

- Convenient online submission

- Rigorous peer review

- Open access: articles freely available online

High visibility within the field

- Retaining the copyright to your article

Submit your next manuscript at $>$ springeropen.com 